\title{
Imanência e transcendência do corpo em Guimarães Rosa
}

Rubens Alves Pereira ${ }^{1}$

João Guimarães Rosa atribui lugar privilegiado aos “corpos” (de seres e coisas) do mundo, inscrevendo-os nas dobras performáticas do seu texto - o tônus da oralidade, o pathos do diálogo, a “espessura" vocabular, as tensões sintáticas ${ }^{2}$. Destaca-se ainda, nesse campo de forças acionado pelo autor, uma diversidade de inscrições dinamizavam o "corpo" dos livros, corpo que ser torna irredutível à condição de mero suporte do texto verbal ${ }^{3}$. Assim, o corpus desta obra encena uma forma de presença semelhante à dos corpos do mundo abertos a determinações mútuas e múltiplas, atravessados por forças dinâmicas, jogos expressivos.

E se é assim na trama da escrita e na conformação dos livros, melhor se configura a complexidade do universo narrado, a movência do mundo. $\mathrm{Na}$ fala prismática do ex-chefe de jagunço e narrador-protagonista Riobaldo Tatarana (Grande sertão: veredas) já se evidencia uma linguagem que se lança no imponderável: "E estou contando não é uma vida de sertanejo, seja se for jagunço, mas a matéria vertente. Queria entender do medo e da coragem, e da gã que empurra a gente para fazer tantos atos, dar corpo ao suceder" (ROSA, 1967, p. 79 - grifos nossos). Reverberar acontecimentos na linguagem, captar a floração do existir. A escrita de Guimarães Rosa mobiliza, em planos e velocidades diversas, o atual e o virtual, o corpo e a alma, o visível e o invisível, o material e o mental.

Na concepção filosófica de Gilles Deleuze, o “acontecimento é uma vibração”, definida por duas componentes: a "extensão" e as propriedades intrínsecas que definem as "séries extensivas", como altura, intensidade, timbre de um som, valor, saturação de cor (Deleuze, 1991,

\footnotetext{
${ }^{1}$ Professor Titular da Universidade Estadual de Feira de Santana. E-mail: rubens@uefs.br

${ }^{2}$ Gilles Deleuze observa que "a sintaxe é um estado de tensão para algo que não é sintático, para algo que nem é mesmo de linguagem (a sintaxe é qualquer coisa que está do lado de fora da linguagem). Em filosofia, a sintaxe é disposta pelo movimento do conceito. Ora, o conceito não se move apenas em si mesmo (compreensão filosófica), move-se também nas coisas e em nós: inspira-nos novos perceptos e novos afectos." (Deleuze, 1996, p.97)

${ }^{3}$ Sob orientação atenta do autor, os livros de Rosa apresentam elementos que dialogam de forma diversa com o texto, como ilustrações de capa, desenhos nas orelhas, índices que se desdobram e ganham ilustrações, aparecendo não só no início, como no final e, às vezes, também nas orelhas dos livros - no caso de Tutaméia, o índice do final propõe modificações no título e, ainda, no estatuto de alguns textos que, de contos, passam a figurar como prefácios disseminados ao longo do livro.
} 
p.119). O "acontecimento", diz ele, "produz-se em um caos, em uma multiplicidade caótica, com a condição de que advenha uma espécie de crivo" (Deleuze, 1991, p. 118).

Este crivo, veremos ao longo do trabalho, passa sobretudo pelo corpo, que é, como afirma José Gil, um "transdutor de códigos”, ou seja, tem "aptidão para emitir e receber signos, para os inscrever sobre si mesmo, para os traduzir uns nos outros" (Gil, 1997, p. 32). Procuraremos demonstrar que Guimarães Rosa, no movimento sui generis da sua linguagem, e em meio às inúmeras forças conjunturais que cruzam seus enredos, busca flagrar o mundo em seu frescor enunciativo, ou seja, em seu devir permanente inscrito na força dos corpos.

Certa vez, questionado sobre as dificuldades de leitura impostas por suas obras, Guimarães Rosa usou um argumento que, deslocando-o de um possível virtuosismo técnico, indica uma espécie de força diferencial investida na linguagem, tornando-a contígua à vitalidade do mundo a linguagem em consórcio íntimo com o quem das coisas. Disse, então, Guimarães Rosa: "Eu não escrevo difícil, eu sei o nome das coisas" (entrevista a Pedro Bloch). Saber o nome das coisas é também, numa dimensão humana e em certa medida, criá-las, rivalizando com a natureza, ou com as miragens do real.

Guimarães Rosa sustém, na alquimia da sua linguagem, pelo menos dois grandes regimes expressivos do mundo: por um lado, adensa quadros concretos de gente e lugar e, por outro, faz deslizar forças, sutis vibrações que distinguem e definem os acontecimentos. Assim é que, "Quando se vem vindo sertão a dentro, a gente pensa que não vai encontrar coisa alguma”, observa um narrador rosiano (Buriti, 1956), como a advertir para os assombros de um aparente vazio, nos ocos daquele mundo. Este vazio, em verdade, acolhe os infinitos movimentos do caos original. O que se entrevê nessa fala ganha forma na reflexão de Riobaldo, a despeito de uma de suas andanças, sertão a dentro, "a esses muito desertos, com gentinha pobrejando. Mas o sertão está movimentante todo-tempo - salvo que o senhor não vê; é que nem braços de balança, para enormes efeitos de leves pesos..." (ROSA,1967, p.391). Corpo vivo, este sertão não determina, antes se comunica radicalmente, troca fluxos com os corpos vivos que nele se entrelaçam.

Essa condição de corpos porosos, "transdutores de códigos", se configura no processo narrativo como um desdobramento natural do mundo em movimento, abismos de virtualidades. "Não sei contar direito", desculpa-se o jagunço-narrador, acrescentando em seguida: "Aprendi um pouco foi com o compadre meu Quelemém; mas ele quer saber tudo diverso: quer não é o caso inteirado em si, mas a sobre-coisa, a outra-coisa” (ROSA, 1967, p. 152). A reflexão metalinguística transborda em ato reflexo de presentificação do corpo vivo no espaço da fala, no fluxo da narrativa. Como diz o filósofo José Gil, 
Porque fala - e se ouve - vivemos o nosso corpo numa presença imediata, (...) inquestionável, do seu sentido (que se confunde com o da sua/da vida). Tem assim a unidade de um sentido que se vive (e não se pensa, não visa um objeto). (...) O corpo, pela voz, contém esta unidade de vida e de sentido (Gil, 1997, p.89).

Desta forma, verificamos que o sujeito da percepção, conforme ainda a fenomenologia de Merlau-Ponty invocada por Gil, está inserido no horizonte percebido. Por um lado, considerando a dimensão referencial, percebe-se este ato-reflexo de implicação mútua na inversão sintática da citada fala de Riobaldo, frase esta recorrente ao longo das cerca de 500 páginas do romance e que modula a reflexão existencial do protagonista como uma espécie de evocação do seu alter ego: “compadre meu Quelemém”. Pela disposição sintática da frase, formula-se uma tensão ou ambiguidade entre uma referência de proximidade, "compadre meu", e uma implicação profunda com o outro, "meu Quelemém”. Noutro sentido, considerando o contexto de enunciação oral, percebe-se ainda esta presença imediata do corpo de Riobaldo no fato de ele estar diante da própria voz, flagrando-se no ato narrativo.

\section{RASTREAR IDEIAS: O CORPO E SEUS DEVIRES}

Riobaldo Tatarana, angustiado narrador-filósofo das terras do sertão e das suas artes e errâncias na guerra e no amor, tem uma privilegiada sensibilidade perceptiva (abertura dos sentidos). Trata-se de uma forma de inteligência corporal que, no fluxo da vida em que se armam os enredos, apreende as forças que definem outros corpos. Trata-se de um ser atento às vibrações sutis, às "pequenas percepções", que são metafenômenos situados em regiões de interface interior/exterior dos corpos. Como diz José Gil (1997, p. 156), “são múltiplos os espaços da alma, e as suas regiões, os seus compartimentos: o corpo é o que multiplica a alma, lhe oferece uma geografia, uma geologia, uma topologia".

Como ponto de partida para estabelecer os parâmetros de um "inconsciente do corpo", ou de uma metafenomenologia que compreende o corpo como um "transdutor de códigos", vejamos mais esta fala metanarrativa de Riobaldo: "Eu quase que nada sei. Mas desconfio de muita coisa. O senhor concedendo, eu digo: para pensar longe, sou cão mestre - o senhor solte em minha frente uma idéia ligeira, e eu rastreio essa por fundo de todos os matos, amém! (ROSA,1967, p. 15).

Nesta prismática fala, observemos, primeiro, que a distância que vai do saber ao desconfiar é de ordem epistemológica e incide sobre a natureza ambivalente e esquiva do "real", em conformidade com o que também expressa o próprio Guimarães Rosa num dos prefácios de 
Tutaméia: "Meu duvidar é da realidade sensível aparente - talvez só um escamoteio das percepções" (Rosa, 1979, p.148). Em outro "prefácio" deste mesmo livro, Rosa ironiza "o terra-a-terra das relações positivas", ou mesmo a falta de "lazer" para "nos ocuparmos em aumentar a riqueza, a beleza, a expressividade da língua. Nem nos faz falta capturar verbalmente a cinematografia divididíssima dos fatos ou traduzir aos milésimos os movimentos da alma e do espírito" (ROSA, 1979, p. 65). Esta captura verbal, como o rastrear de Riobaldo, é sobretudo um investimento do corpo e do espírito, da intuição e da inteligência. "Cão mestre" no "pensar longe" uma encarnada “ideia ligeira”, Riobaldo concebe o ato perceptivo da vida não como pura especulação mental, mas como uma força viva a "rastrear" ideias, a recortar suas direções e volumes no corpo do mundo, no "fundo de todos os matos". A vida, assim vertendo desse "espaço limiar entre interior e exterior", é petição de milagre nos confins da alma: "Sertão: é dentro da gente" (p. 235), diz Riobaldo.

Ao descrever o complexo processo de articulação entre o interior e o exterior do corpo, José Gil chega ao conceito de "infralíngua", sendo esta uma dimensão expressiva fundamental para enfrentar o desafio sugerido, e assumido por Guimarães Rosa, qual seja, o de "capturar verbalmente a cinematografia divididíssima dos fatos ou traduzir aos milésimos os movimentos da alma e do espírito". Atento às “metamorfoses do corpo", Gil argumenta que "se deve entender a infralíngua como resultado de um processo de incorporação da linguagem verbal, ou melhor, da sua inscriçãosedimentação no corpo e nos seus órgãos" (Gil, 1997, p. 46). Com isso, o corpo, na "plasticidade do seu próprio espírito", adquire uma inteligência que vai

refluir, por sua vez, sobre a linguagem e o intelecto puro: vai neles induzir movimentos subtis, associações, impregnações, contaminações semânticas imperceptíveis mas decisivas que testemunham a transformação do espírito numa espécie de grande corpo felino capaz de intuições, pressentimentos, fulgurações, "sextos sentidos" que só o pensamento por imagens pode fornecer. (Gil, 1997, p. 46)

Essa infra-língua, além de responsável pelos processos imaginativos, possibilitaria "introduzir no pensamento lógico (e no conceito) o movimento propriamente empírico do corpo e das coisas" (Gil, 1997, p. 47). O conceito de "significante flutuante" é importante para se chegar ao processo constitutivo da infralíngua, das “pequenas percepções”. Sistematizado pelo filósofo no início do seu livro Metamorfoses do corpo, este conceito de "significante flutuante" se sustenta no fato de que há um "excedente de significação" no mundo não abarcado pelos signos: "há sentido, há significado, mas é impossível atribuir-lhe um sentido referenciável e preciso". Este fato configura uma "espécie de zona de indeterminação" entre significante e significado e explicaria, segundo José 
Gil (citando Lévi-Strauss), "todos os aspectos semânticos estranhos de certas noções primitivas como mana, que parecem pertencer a todos os códigos - as coisas têm um mana, assim como as plantas, os homens (...)". Ainda citando o antropólogo, Gil explica que "estes significantes flutuantes não designariam nada de preciso, teriam muito simplesmente "um valor simbólico zero"”. Enfim, o "significante flutuante (...) designa sempre uma energia, uma força que é impossível ver significada em códigos", e tem o mérito de possibilitar "o exercício do pensamento simbólico". (Gil, 1997, p. 16-9).

A partir desses princípios, José Gil identifica na infralíngua "um procedimento geral para pensar o mundo, quer dizer, para que o mundo sensível, variável, caótico, adquira ordem e sentido”. Nesse processo, diz ainda o filósofo, "as articulações do corpo deixam circular a energia. O essencial do significante flutuante é manifestar a vida no que ela tem de imprevisível, de variado e de espontâneo" (Gil, 1997, p. 47-8). Saber acionar tais significantes é fazer falar o corpo, colocá-lo em comunicação com os corpos do mundo: "O sertão está em toda a parte", assoma Guimarães Rosa (ROSA, 1967, p. 9). Vamos enfocar mais diretamente alguns elementos representativos dos enredos de Rosa. Destacaremos, inicialmente, uma cena de Sagarana, e para concluir, faremos alusões a cenas de Grande Sertão: Veredas.

\section{A HORA E A VEZ DE NHÔ AUGUSTO ESTÊVES MATRAGA}

"Matraga não é Matraga, não é nada. Matraga é Estêves. Augusto Estêves, filho do Coronel Afonsão Estêves, das Pindaíbas e do Saco-da-Embira. Ou Nhô Augusto - o homem...” (ROSA, 1980, p. 324). Assim começa o conto "A hora e a vez de Augusto Matraga", com este jogo de identidades do protagonista. Após a negativa da primeira frase ("Matraga não é Matraga, não é nada."), que contraria o título logo acima, o apelido "Matraga" só voltará a aparecer no finalzinho do conto, após as quase 50 páginas em que o penitente Nhô Augusto vai cumprindo a sua sorte de valentão que quer se converter. Inicialmente, homem desregrado, amigo do jogo, valente-brigador, desrespeitoso. Depois de uma espécie de morte e renascimento, converte-se em cristão penitente em busca da salvação. Por fim, o encontro e o confronto com Joãozinho Bem-Bem, seu amigo de sina jagunça.

Filho de Coronel rico, o destemido Nhô Augusto vai passar por muitas provações: com a morte do pai, acaba por perder os bens da família; sua mulher foge com outro homem, levando a filha; seus homens de luta debandam para o lado de um fazendeiro inimigo, que o ameaça de morte. Ao enfrentar, sozinho, este inimigo, é dominado, espancado e, já desfalecido, é ferrado, não sendo morto porque, no calor do ferro quente, desperta em sobressalto e se atira num precipício, sendo 
dado como morto por seus algozes. Do fundo do precipício renasce, resgatado e tratado por um casal de negros velhos. Vai aos poucos se recuperando, recebe visita de padre, confessa suas dores e arrependimentos e promete buscar a salvação eterna. Antes de fugir para longe, confins do dentro, faz um estranho pacto de auto-salvação, ajoelhado no meio da estrada, braços abertos em cruz: “ - Eu vou p'ra o céu, e vou mesmo, por bem ou por mall... E a minha vez há de chegar... P’ra o céu eu vou, nem que seja a porrete!...” (p. 340). Forçado penitente, segue este personagem em busca incerta de salvação, até encontrar a sua hora e vez no endemoniado combate com Joãozinho BemBem e seu bando. O primeiro e amigável encontro se deu no pequenino povoado em que Nhô Augusto se recolhera do mundo:

O bando desfilou em formação espaçada, o chefe no meio. (...) de olhar dominante e tosse rosnada, mas sorriso bonito e mansinho de moça - era o homem mais afamado dos dois sertões do rio: (...) maior do que Antônio Dó ou Indalécio; o arranca-toco, o treme-terra, o come-brasa, o pega-à-unha, o fechatrêta, o tira-prosa, o parte-ferro, o rompe-racha, o rompe-e-arrasa: Seu Joãozinho Bem-Bem (ROSA, 1980, p. 348).

E o jagunço é só altas presenças para medo e espanto de todos. Mansidão de tigres e cobras, imprevisto no seu bastante proceder. No calor da novidade, Nhô Augusto caminha, meio desengonçado, ao encontro do famoso bando de jagunços, e recebe a imediata simpatia do chefe: "Não debocha, companheiro, que eu estou gostando do jeito deste homem caminhar", assim ele repreende um de seus seguidores que tal procedia (ROSA, 1980, p. 349). Joãozinho Bem-Bem e seu bando são hospedados na casa de Nhô Augusto, recebendo veneração e cuidados especiais. A profunda empatia do chefe jagunço com Matraga leva-o a convidá-lo a fazer parte do bando, tentação a que Nhô Augusto resiste.

O segundo e definitivo encontro dos dois (e que mais nos interessa aqui) se dá no arraial do Rala-Côco, onde Matraga chegou por acaso, após vagar pelo mundo, em penitência desatinada. Ao saber que Joãozinho Bem-Bem estava arranchado no local com seus jagunços, Matraga logo se dirige ao distinto amigo, sendo muito bem recebido: "Fitava Nhô Augusto com olhos alegres, e tinha no rosto um ar paternal. Mas, na testa, havia o resto de uma ruga” (ROSA, 1980, p. 363). Um resto de "ruga" na testa, como a desconfiar, Joãozinho Bem-bem, do movimento sorrateiro do mundo... O imprevisto "mano velho", Nhô Augusto.

Aconteceu que um dos jagunços do bando foi morto por um rapaz daquela cidade, que conseguiu fugir. O pai do criminoso é intimado a responder, devendo a pena recair sobre sua família. "O velhote chorava e tremia" ajoelhado aos pés do chefe jagunço, suplicante ao extremo, evocando a piedade daquele homem, se oferecendo em sacrifício de morte e, por fim, apelando às forças divinas: “... Pelo sangue de Jesus Cristo e pelas lágrimas da Virgem Maria!...”. Ao que 
Joãozinho Bem-Bem, categórico, após evocar o código jagunço, sentencia: "Um dos dois rapazinhos seus filhos tem de morrer, de tiro ou à faca, o senhor pode é escolher qual deles é que deve pagar pelo crime do irmão. (...) as mocinhas são para os meus homens”. Esgotadas as vãs súplicas, "o velho, sem se levantar (...), hirto, cordoveias retesas, mastigando os dentes e cuspindo baba, urrou: - Pois então, satanaz, eu chamo a força de Deus p'ra ajudar a minha fraqueza no ferro da tua maldição!...” (ROSA, 1980, p. 366). Silêncio de profundos ecos na sala. Do fundo sem margem do silêncio, Matraga pede ao amigo Joãozinho Bem-Bem o perdão para o velhote, que, no zelo da família, evocara "Nosso Senhor" e a "Virgem Maria":

Nhô Augusto tinha falado; e a sua mão esquerda acariciava a lâmina da lapiana, enquanto a direita pousava, despreocupada, no pescoço da carabina. Dera tom calmo às palavras, mas puxava forte respiração (....). Os olhos cresciam, todo ele crescia, como um touro que acha os vaqueiros excessivamente abundantes e cisma de ficar sozinho no meio do curral (ROSA,1980, p. 367 - grifo nosso).

O chefe jagunço perguntou se ele estava caçoando, e Nhô Augusto respondeu que não: "Estou pedindo como amigo, mas a conversa é no sério, meu amigo, meu parente, seu Joãozinho Bem-Bem". Ao que retruca o valente, do alto da sua superioridade de afamado chefe de jagunço: "Pois pedido nenhum desse atrevimento eu até hoje nunca que ouvi nem atendi!...". Atmosfera pesada, "o velho engatinhou, ligeiro", para um canto de parede; "no calor da sala, uma mosca esvoaçou". E então, Nhô Augusto como que desatina:

Pois então... - e Nhô Augusto riu, como quem vai contar uma grande anedota ... Pois então, meu amigo seu Joãozinho Bem-Bem, é fácil... Mas tem que passar primeiro por ríba de eu defunto...

Joãozinho Bem-Bem se sentia preso a Nhô Auguisto por uma simpatia poderosa, e ele nesse ponto era bem assistido, sabendo prever a viragem dos climas e conbecendo por instinto as grandes coisas. Mas Teófilo Sussuarana era bronco excessivamente bronco, e caminhou para cima de Nhô Augusto. Na sua voz:

- Êpa! Nomodopadrofilhospritossantamên! Avança, cambada de filhos-da-mãe, que chegou minha vez!...

E a casa matraqueou ... (...) Nhô Augusto gritando qual um demônio preso e pulando como dez demônios soltos (ROSA, 1980, p. 367 - grifos nossos).

$\mathrm{Na}$ confusão infernal do combate, alguns jagunços caem mortos, outros fogem e Nhô Augusto e Joãozinho Bem-Bem, já sem munição, mas em júbilo de luta fraternal, rolam para a rua com facas em punho. Nhô Augusto, mesmo cravado de balas, consegue ferir o adversário. Agonizando, Joãozinho Bem-Bem elogia a valentia do adversário, se confraterniza e propõe amizade naquela hora extrema: "Estou no quase, mano velho... (...) Quero acabar sendo amigos..." (ROSA, 1980, p. 369). Pouco depois, morre também Augusto Matraga, satisfeito de ter chegado a 
sua hora e vez de reatar as pontas do destino nele enredado.

No que pese o esforço de contextualização dos fatos e a longa citação dos momentos decisivos, interessa-nos destacar a profunda afinidade entre Nhô Augusto e Joãozinho Bem-Bem, o jogo de forças psicofísicas que se instaura entre eles. Tendo simpatizado com o seu "mano velho" a partir do jeito de andar; Joãozinho Bem-Bem sabia "prever a viragem dos climas" e conhecia "por instinto as grandes coisas". Nos atos e falas, nos gestos e expressões corporais de Nhô Augusto se inscreviam, para o valente chefe jagunço, os "signos flutuantes" de uma força distinta, de uma personalidade exemplar. No momento mais agudo, em que a realidade aparente se cala e o silêncio fantasmagórico evidencia o esvoaçar de uma mosca e a "viragem dos ventos", corpo e espírito se potencializam: "os olhos (de Nhô Augusto) cresciam, todo ele crescia, como um touro que acha os vaqueiros excessivamente abundantes e cisma de ficar sozinho no meio do curral". Joãozinho Bem-Bem "se sentia preso a Nhô Augusto por uma simpatia poderosa", mas não teve tempo de domar o acontecer das coisas, pois o "bronco excessivamente bronco" jagunço Teófilo Sussuarana não tem o dom das "pequenas percepções", não sabe o que está se passando nas micro-frequências daquele instante, e avança para o manso e endemoniado Matraga. Esquivo em seus modos de homem pacato, Nhô Augusto induz Teófilo Sussuarana ao equívoco do ataque.

De um modo geral, como argumenta José Gil, “a relação indicada pelo corpo do outro inaugura uma diferença irredutível: entre o que mostra e o que esconde, ao nível mesmo da percepção simples. Percepcionar um corpo outro significa, antes de mais, sofrer uma esquiva e compensá-la com um equívoco”. Este espaço diferencial pode ser atenuado quando se visa, diante do corpo do outro, "O seu vivido", ou melhor, "a sua 'alma' com tudo o que ela comporta de afectos e pensamentos”. Diz ainda o filósofo que “o visar não se dirige a um 'sentido', a uma 'essência', mas a um contato vital; 'comunicar' com outrem é entrar em contato, misturar substâncias". Por sua vez, o "misturar substâncias que se visa", diz ele, "é um conhecimento imediato pela afectividade" (GIL, 1997, p. 148). Apenas Joãozinho Bem-Bem consegue estabelecer esse "contato vital" com Augusto Matraga, no calor daquela grande presença de homens em armas.

Na cena em que Riobaldo Tatarana, em Grande sertão: veredas, se torna o chefe Urutú-Branco, a configuração do enredo se parece com a da cena decisiva de Augusto Matraga com Joãozinho Bem-Bem. Contudo, no caso do manso desafio de Riobaldo ao destemido chefe Zé Bebelo, o desenlace ganha novos rumos, fazendo desta cena um momento de aprendizagem em relação à anterior, já que as duas passagens são marcadas por citações que as aproximam direta e indiretamente. Vejamos alguns pontos: na relação entre os contedores, verifica-se que Nhô Augusto conhecia e admirava o legendário Joãozinho Bem-Bem, tendo-o servido em sua própria 
casa; Riobaldo serviu ao chefe Zé Bebelo, a quem admirava como sendo homem exemplar em sua sabedoria e inteiro em sua coragem: "medo, ou cada parente de medo, ele cuspia em riba e desconhecia”, diz Riobaldo (GSV, p. 101). Quanto aos dois chefes jagunços, informa a crítica Kathrin H. Rosenfield (1992, p. 72) que, seguindo a "regra de ferro de Joãozinho Bem-Bem", Zé Bebelo "é um defensor da castidade guerreira que desvia as energias sexuais para a destruição sangrenta".

Por outro lado, para todos (Matraga, Riobaldo e Zé Bebelo), Joãozinho Bem-Bem é mito supremo: diz Riobaldo que seu “exemplo, em nomes”, além de Joca Ramiro e Sô Candelário, foi Joãozinho Bem-Bem (ROSA, 1967, p. 212), e que este, era "o mais bravo de todos, ninguém nunca pode decifrar como ele por dentro consistia” (ROSA, 1967, p. 16). Por sua vez, Zé Bebelo admite: "O único homem-jagunço que eu podia acatar (...) já está falecido” e, como informa Riobaldo, este homem era "Joãozinho Bem-Bem, das Aroeiras". Acrescenta-se ainda que Zé Bebelo "tinha estudado a vida dele (Joãozinho Bem-Bem), nos pormenores, com tanta devoção especial, que até um apelido em si se pôs: Zé Bebelo, causa que, de nome, em verdade, era José Rabêlo Adro Antunes" (ROSA, 1967, p. 101-2).

Joãozinho Bem-Bem e Zé Bebelo, quando afrontados, gozavam de uma aparente superioridade, tanto pela merecida fama, como pelo apoio dos seus seguidores. Por outro lado, Matraga e Riobaldo são pactários, aquele com as forças divinas em busca da salvação da alma; este, com as forças demoníacas, em busca de poder pessoal. Se uma forte empatia une Matraga e BemBem, o mesmo se pode dizer de Riobaldo e Zé Bebelo. Se Joãozinho Bem-Bem conhece "por instinto as grandes coisas", Zé Bebelo "pegava no ar as pessoas", como disse Riobaldo (ROSA, 1967, p. 61), para quem, "criatura assim sente tudo adivinhado, de relâmpago, na ponta dos olhos da gente" (ROSA, 1967, p. 198).

Pouco antes do desafio a Zé Bebelo, Riobaldo passa por alguns fenômenos que sinalizam um estado excepcional de forças instintivas (em verdade, age fortemente nele a nebulosa experiência vivenciada nas "Veredas-Mortas", de pactário com o Demo). Primeiro, Riobaldo domina um grupo de cavalos que se espanta com a sua chegada; depois, para outras surpresas, faz o vistoso cavalo de seô Habão dobrar-se a seus pés. O avarento Habão, implacável comerciante, no impacto daquele insólito acontecimento, oferece ao jagunço o cavalo, com sela e arreios: "O seô Habão estava ali, me desentendeu nos olhos”, constata Riobaldo. Tão distinto presente, além de obrigá-lo a sustentar-se ante a inveja dos companheiros, intuiu Riobaldo, era tanto uma afronta ao chefe Zé Bebelo, como também um sinal para si, um sinal para todos: "Um dom de tanto quilate tinha de ser para o Chefe. Reconheci, aí. Mas não tirei para trás (...) Um qualquer chefe de jagunço havia de 
ter ímpeto de resolver aquilo fatal. (...) Pensei o dito, num ínterim. E pensei pontudo em minhas armas" (ROSA, 1967, p. 326 - grifo nosso).

Com a chegada de Zé Bebelo, começa um duelo sorrateiro entre os dois, um jogo de esquivas e insinuações, sobredeterminado pela presença viva, expansiva, dos corpos. Trava-se uma luta invisível e pouco definida racionalmente, luta geradora de tensões que mobilizam corpo e alma. Riobaldo, no seu ainda informe querer, lança uma pergunta aos jagunços, direcionado-a para os dois chefes presentes, João Goanhá e Zé Bebelo, sobretudo a este, o principal. "Não exclamei, não pronunciei; só disse: - ‘Ah, agora quem aqui é que vai ser o Chefe?” (ROSA, 1967, p. 329). Ante a indecisão ou a confusão provocada, a inesperada pergunta vai sendo repetida por Riobaldo e, a cada repetição, os corpos, em performances, adquirem predisposições variadas e as forças mentais e psicológicas vão se alterando.

"Eu não queria afrontar ninguém. Até com preguiça eu estava", admite Riobaldo, que no preciso momento desconhecia ainda a extensão da sua voz e a conformação do seu desejo. Com o desdobrar da inocente, mas também certeira pergunta, ele vai tomando ciência de que algo de novo estava sendo gestado, ou melhor, já estava ganhando corpo ali, na presença de todos: "com meus olhos, tomei conta” (ROSA, 1967, p. 329), diz o protagonista.

“Quem é que é o chefe?!' - repeti”. Zé Bebelo “pardejou”, diz Riobaldo. Quanto a João Goanhá: "eu vi, aquele mestre quieto se mexer, em quente e frio, diante de minhas vistas - nem não tinha ossos: tudo nele foi encurtando medida - gesto, fala, olhar e estar". Imerso ainda numa zona de indeterminação, arremata o narrador: "Nenhum deles. E eu - Ah - eu era quem menos sabia - porque o Chefe já era eu. O Chefe era eu mesmo! Olharam para mim.” (ROSA, 1967, p. 329-30).

Como diz José Gil, “somos um 'movimento para': e conforme a fricção, a resistência, o peso, a leveza, a opacidade dos diferentes suportes, esse movimento adquire ou não velocidade expressiva, quer dizer que permite à alma exprimir-se" (GIL, 1997, p. 162). Riobaldo lograva exprimir-se Chefe, vontade soberana expressa na voz e nos gestos, no visível e no inconsciente do corpo. Dois jagunços tentam reagir ao desafio agora patenteado, mas são prontamente mortos a tiro por Riobaldo. "Esbarrados em tanta singeleza de choques", todos permanecem quietos, diz Tatarana, observando, como Augusto Matraga, que chegara o seu momento: “Ali, era a hora”. E ali, nesse "de barba a barba" com "Zé Bebelo, homem disposto e que "não conhecia medo", era de se esperar "um sangue ou sangues". Contudo, "Zé Bebelo retardou", astuto: "Eu social, encostado. Conheci que ele tardava e pensava, para ver o que fazer mais vagarosamente". 
Joãozinho Bem-Bem, vimos, sente a dimensão do confronto mas não teve oportunidade de decidir, por causa da precipitação de um outro jagunço, bem como pela pré-disposição de Augusto Matraga. Por sua vez, Zé Bebelo, que conhece a história de Joãozinho Bem-Bem e como ele é bem servido de instinto, não se precipita, pois pressente diante de si um homem determinado e na posse de todas as suas superiores forças, físicas e mentais. Zé Bebelo "não tremeu, no sucinto dos olhos", mas reconheceu o direito de Riobaldo, ali adquirido com sua alta presença. Deu-lhe, inclusive, o epíteto de Urutú-Branco (cobra voadeira).

Já Chefe empossado e no comando de jagunços, Urutú-Branco chega à fazenda de seo Ornelas, "homem bom descendente", na posse tranquila e segura de si. Nos desvãos da curiosidade, Riobaldo confere com um dos seus homens o dito passado de valentia daquele velho, que teria cerca de "sessenta ou oitenta mortes contáveis...". Foram bem recebidos, e Riobaldo foi tratado com as honrarias de grande chefe jagunço. Na sua mansa cordialidade, regente e zeloso chefe de família, seo Ornelas impressiona e mesmo desestabiliza o chefe jagunço, que se sente ameaçado em sua (auto) imagem. O chefe Urutú-Branco vacila ante a inabalável (e imponderável) brandura do velho, mesmo tendo, ao alcance dos imprevistos jagunços, "três ou quatro filhas, e outras parentas, casadas ou moças, bem orvalhosas". (p. 342)

É como se seo Ornelas trouxesse em si algo de Augusto Matraga, e do próprio Riobaldo, que da mansidão se arvoraram mais fortes que seus adversários, chefes de fama estabelecida. A aparente vantagem de Riobaldo poderia não se fazer valer:

... ele conseguia as ponderadas maneiras, cidadão, que se representava; que, isso, ainda que eu pelejasse constante, tarde seria para bem aprender. $\mathrm{Na}$ verdade. Aquela hora, eu, pelo que disse, assumi incertezas. Espécie de medo? Como que o medo, então, era um sentido sorrateiro fino, que outros e outros caminhos logo tomava. (p. 343).

"O sertão é confusão em grande demasiado sossêgo", vaticina seo Ornelas, quieto em sua toda presença. "Procurando encorpar (sua) vantagem", Riobaldo inquieta-se: faz de conta que não está ouvindo, desvia o olhar, irrompe com outras conversas. Agastado com aquela incômoda situação, o chefe jagunço busca âncora para a sua superioridade. Dizendo-se conduzido pelo olhar ciumento de Diadorim, ele nota uma distinta mocinha e decide chamá-la para perto de si, mobilizando forças, condensando o momento com os diferentes sobressaltos das pessoas presentes. Riobaldo, na tensão daquele confronto sinalizado, especula mentalmente sobre os prazeres sexuais que ele poderia requisitar, do alto do seu império jagunço: prontamente mataria seo Ornelas, desarmaria Diadorim, caso este reagisse, e pegaria nos braços a "menina-mocinha".

Como Joãozinho Bem-Bem, ele poderia arbitrar sobre o destino funesto de uma indefesa 
família, matando e desonrando as mulheres. Só que o velho Ornelas se insinuava, no medo sagaz de Riobaldo, como uma espécie de valente imprevisto por trás da quieta criatura, a exemplo de Augusto Matraga na defesa da família ameaçada por Joãozinho Bem-Bem. Ele próprio, Riobaldo, no macio da fala e com aparente desvantagem, não afrontara Zé Bebelo? Além do mais, seria preciso enfrentar também Diadorim, atônito no fluir daquele instante.

Rastreando por todos os matos as suas tentações (de auto-afirmação e prazer) e as forças em jogo, Riobaldo consegue plantar uma insidiosa ideia nos tumultos da alma e do corpo, ideia que agregou uma força capaz de estabelecer em si um pathos e um pacto diferentes, mudando os rumos do seu proceder, evitando assim um duvidoso confronto, sem a desonra da fraqueza patenteada ou do medo estatuído:

\footnotetext{
A mocinha me tentando, com seu parado de águas; a boniteza dela esteve em minhas carnes. Ela perigou. Não perigou: no instante achei em minha idéia, adiada, uma razão maior - que é o sutil estatuto do homem valente. Aquela formosura, aquela delicadezazinha, então podiam mesmo ser assim, em toda segurança, feito ela fosse, por um exemplo, filha minha. A mocinha, eu de repente queria, eu gostava de dar a ela muito forte proteção (ROSA, 1967, p. 345 - grifos nossos).
}

Com isso, ainda soberano de si, Riobaldo consegue estabelecer um outro crivo para o desdobrado enredo, um outro final para o teatro de forças ali instaurado. O protagonista toma seus enredos nas mãos e consegue sair daquele lugar assinalado: lugar fatal, para Joãozinho Bem-Bem, e vexatório, para Zé Bebelo. Com a percepção liberta que não teve Augusto Matraga, e com as condições circunstanciais que faltaram a Joãozinho Bem-Bem e, em certo sentido, a Zé Bebelo, o narrador-protagonista do Grande Sertão, Riobaldo Tatarana, logrou encontrar, de novo, a sua hora e vez.

Para concluir, faremos apenas uma breve referência a Diadorim, no que se refere à interdição do seu corpo feminino - mulher travestida de homem. "Ele, o menino, era dessemelhante, já disse, não dava minúcia de pessoa outra nenhuma”, conforme Riobaldo, acrescentando que era "comparável um suave de ser, mas asseado e forte - assim se fosse um cheiro bom sem cheiro nenhum sensível - o senhor represente" (p. 82 - grifo nosso). Essa dessemelhança, fruto da interdição ou desvio do feminino, atordoa Riobaldo. Impossibilitada de exercer a feminilidade no próprio corpo, Diadorim busca fora de si, na natureza diversa (os pássaros e seus cantos, os animais, as plantas, os fenômenos naturais), um espaço possível para encarnar a delicada sensualidade e a acolhedora sensibilidade que definem a sua encoberta condição feminina. O mundo torna-se minúcias de sedução: 
Lhe mostrar os altos claros das Almas: rio despenha de lá, num afã, espuma próspero, gruge; cada cachoeira, só tombos. O cio da tigre preta na Serra do Tatú - já ouviu o senhor gargaragem de onça? A garoa rebrilhante da dos-Confins, madrugada quando o céu embranquece - neblim que chamam de xererém. Quem me ensinou a apreciar essas belezas sem dono foi Diadorim... (ROSA, 1967, p. 23 - grifos nossos).

$\mathrm{Na}$ natureza, a donzela-guerreira encontra um corpo capaz de acolher o seu amor e disseminá-lo no outro, sem macular o seu segredo, sem constranger o seu amado. Essa experiência transversa do amor e da pulsação feminina de Diadorim marcam profundamente Riobaldo, alimentando-lhe o olhar poético que recorta o sertão e potencializando-lhe, pela memória afetiva, a própria narrativa.

"Diadorim me pôs o rastro dele para sempre em todas essas quisquilhas da natureza. (...) Diadorim, duro sério, tão bonito, no relume das brasas" (ROSA, 1967, p. 25), diz Riobaldo, irremediavelmente marcado por este ser-mulher, por esta força feminina encarnada no mundo, e impregnada no canto. E pôs-se a fábula em ata...

\section{REFERÊNCIAS}

DELEUZE, Gilles. A dobra: Leibniz e o barroco. Trad.Luiz Orlandi. Campinas, SP: Papirus, 1991. DELEUZE, Gilles. O mistério de Ariana. Trad. de Edmundo Cordeiro. Lisboa: Veja, 1996.

GIL, José. Metamorfoses do corpo. Lisboa: Relógio D’Água Editores,1997.

ROSA, João Guimarães. Sagarana. 23. ed. Rio de Janeiro: José Olympio, 1980.

ROSA, João Guimarães. Grande Sertão: Veredas. 5. ed. Rio de Janeiro: José Olympio, 1967.

ROSA, João Guimarães. No Urubuquaquá, no Pinhém. 5. ed., Rio de Janeiro: José Olympio, 1978.

ROSA, João Guimarães. Primeiras Estórias. 2. ed., Rio de Janeiro: José Olympio,1964.

ROSA, João Guimarães. Tutaméia (Terceiras Estórias). 5. ed., Rio de Janeiro: José Olympio, 1979.

ROSENFIELD, Kathrin H. Grande Sertão: Veredas - Roteiro de leitura. São Paulo: Ática, 1992. 